\title{
Sleep deprivation, pain and prematurity: a review study
}

\author{
Privação do sono, dor e prematuridade: um estudo de revisão \\ Kelly Cristina Santos de Carvalho Bonan ${ }^{1}$, João da Costa Pimentel Filho², Rosana Maria Tristão², \\ José Alfredo Lacerda de Jesus², Dioclécio Campos Junior ${ }^{2}$
}

\begin{abstract}
The aim was to describe current reports in the scientific literature on sleep in the intensive care environment and sleep deprivation associated with painful experiences in premature infant. A systematic search was conducted for studies on sleep, pain, premature birth and care of the newborn. Web of Knowledge, MEDLINE, LILACS, Cochrane Library, PubMed, EMBASE, Scopus, VHL and SciELO databases were consulted. The association between sleep deprivation and pain generates effects that are observed in the brain and the behavioral and physiological activity of preterm infants. Polysomnography in intensive care units and pain management in neonates allow comparison with the first year of life and term infants. We have found few references and evidence that neonatal care programs can influence sleep development and reduce the negative impact of the environment. This evidence is discussed from the perspective of how hospital intervention can improve the development of premature infants.
\end{abstract}

Keywords: sleep, pain, prematurity, polysomnography, neonatal intensive care.

RESUMO

O objetivo foi descrever o estado atual na literatura científica sobre privação do sono associado a experiências dolorosas no prematuro e o papel na evolução do sono em ambiente de terapia intensiva. Realizou-se uma busca sistemática para estudos sobre sono, dor, prematuridade e programas de atenção ao neonato. Foram consultados as bases Web-of-Knowledge, MEDLINE, LILACS, Biblioteca Cochrane, PubMed, EMBASE, Scopus, BVS e SciELO. A associação entre privação do sono e dor gera efeitos que são observados na atividade cerebral, fisiológica e comportamental dos prematuros. A polissonografia nas unidades intensivas e o manejo da dor em neonatos permitem comparação no primeiro ano de vida com crianças nascidas a termo. Encontraram-se poucas evidências de que programas de cuidado neonatal podem influenciar o desenvolvimento do sono e diminuir o impacto negativo do ambiente. Estas evidências são discutidas na perspectiva de como a intervenção hospitalar pode melhorar o desenvolvimento do prematuro.

Palavras-chave: sono, dor, prematuridade, polissonografia, terapia intensiva neonatal.

In recent decades there has been a considerable increase in the number of premature births and in the survival rate of these babies as a consequence of also increasing the effectiveness of intervention in Neonatal Intensive Care Unit (NICU). This relatively recent phenomenon has opened various fronts of research on the development of the fetus outside the uterus and its challenges. Among the areas that have aroused more interest and generated publications are the investigations on the development of sleep and pain perception and the future implications of sleep deprivation and exposure to pain at early ages. The uterine environment is suitable for the full growth and development of the human fetus site. The challenge of preterm birth and hospitalization in the NICU promotes an abrupt environmental difference for newborns which can bring challenges for future development. The instability of body temperature, weight loss, respiratory stress, and continuous exposure to invasive procedures possibly perceived as painful, cardiac instability and neurodevelopment disorders are common characteristics of premature infants, especially those with very low weight, under 30 weeks and subjected to long periods of hospitalization ${ }^{1,2}$.

Neurodevelopment changes result mainly of early birth between late second or early third trimester of pregnancy, during which the cerebral cortex and subcortical network are immature and neuronal organization of the frontal lobe has not yet occurred ${ }^{3}$. A case-control study conducted in

${ }^{1}$ Universidade de Brasília, Hospital Universitário de Brasília, Centro de Enfermagem em Neonatologia, Brasília DF, Brazil;

${ }^{2}$ Universidade de Brasília, Faculdade de Medicina, Brasília DF, Brazil.

Correspondence: Kelly Cristina Santos de Carvalho Bonan; Universidade de Brasília, Hospital Universitário de Brasília; SGAN, 605; 70830-200 Brasília DF, Brasil; E-mail: kellytitina@gmail.com

Conflict of interest: There is no conflict of interest to declare.

Received 22 May 2014; Received in final form 14 October 2014; Accepted 03 November 2014. 
premature of very low birth weight indicate that the incidence of moderate to severe brain damage ranges from $15 \%$ to $25 \%$, and behavior problems and academic skills are present in $40 \%$ of subjects from the beginning of school life ${ }^{4}$. Brain damage can still bring delayed cognitive, motor and sensory system dysfunction. Indeed, more than $50 \%$ of children and adolescents born preterm have needed the support of special education and monitoring by mental health services throughout their life $\mathrm{e}^{5,6,7}$.

While NICU is essential for the survival of newborns, the invasive environment, constant exposure to light, high noise level and noxious interventions generate stimuli that overload and damage the sensory system, and may have deleterious effects, changing the immature brain and its further development. All these adverse conditions for development may have direct implications in the short or long term, in some physiological functions with behavioral implications for the prematurely born baby and its development. Among the most important and least studied physiological functions in this population is the development of sleep and its close relationship with the history of repeated experiences of pain in the neonatal period. Although much has been investigated on sleep and pain in premature, it can be stated that little is known. However, a new line of research has attracted interest, which is the interrelationship between the neurophysiological processes associated with sleep and pain in patients born prematurely. This article seeks to outline the information available in the literature on this interrelationship.

\section{METHOD}

The literature review was performed up to October 2013. Prematurity, sleep, pain, intensive care and neonatal polysomnography were the descriptors used. Original research and reviews were considered.

\section{RESULTS}

\section{The Premature and their environment}

Prematurity is marked by sudden changes in the quality and intensity of sensory information reaching the baby by all modes. The child in the womb is exposed to a sound intensity level around 40-60 decibels $(\mathrm{dB})$ while in the NICU environmental noise can reach 70-80 dB. This kind of change can cause or enhance the occurrence of apneas, bradycardia, changes in blood pressure and cerebral blood flow. The constant artificial lighting can interfere with visual development, increase the incidence of strabismus and cause changes in the circadian rhythm ${ }^{8,9}$. These physiological changes occur due to the immaturity of the Central Nervous System
(CNS), which has decreased autoregulation and autonomic capabilities to deal with stress, and cannot limit or selectively inhibit the stimuli received; consequently, it produces an impact on the physiological balance.

The incidence of neurobehavioral changes remains high and problematic when evaluating the effect of prematurity on the development of the newborn. Among the factors contributing to these changes are low birth weight and stress caused by the NICU environment. It is considered that the immature nervous system of preterm newborns may be insufficient to process multiple and excessive stimuli compared to what a newborn baby usually receives, including repeated nociceptive stimuli of painful and invasive activities of nurses and neonatologists in their daily actions during the prolonged stay of the infant ${ }^{9}$.

\section{Sleep and prematurity}

Sleep varies significantly both in its structure and in its functions with age. In the neonatal period it has a connection with the maturation of CNS, memory consolidation and learning, maintaining energy, increased protein synthesis and secretion of growth hormone (GH). The mechanisms involved in sleep and wakefulness are present even before birth, and these are developed thanks to the circadian cycle (CC), which like other biological cycles is characterized by maintaining physiological functions ${ }^{1,7,10}$.

The CC is generated at $18-20^{\text {th }}$ week of gestation in the anterior hypothalamus, specifically in the suprachiasmatic nucleus. At any age, it's generated endogenously, and modulated by exogenous factors such as light ${ }^{1,11,12}$. Recent studies show that the circadian system is responsive to light in the $24^{\text {th }}$ week of pregnancy, and low intensity of light can regulate the development of the biological clock ${ }^{1}$. The cycles of sleep and wakefulness in the fetus vary between 40 and 60 minutes and the sleep pattern is characterized by long periods ranging from minutes to hours ${ }^{13}$. In the last trimester, the sleep-wake cycle of the fetus falls in line with maternal sleep-wake cycle, so maternal diseases that alter this cycle or the occurrence of premature birth may alter the development of the circadian rhythm of the child. These effects may be temporary, but primarily affect the most premature infants $^{13}$. Newborns sleep about $70 \%$ of the 24 hours and adults sleep 25\%-30\%, 50\% more than adults, suggesting a strong relationship between sleep and growth, including brain growth ${ }^{14}$.

Evidence from animal models has shown that rats deprived of sleep have around $6 \%-8 \%$ reduction in the number of neurogenesis explaining how sleep deprivation has a profound effect on synaptic plasticity and cognitive performance. The organization of the $\mathrm{CC}$ is associated with neural maturation of neonates. The cycle is perceived immediately after birth, but with the new environment, it is no longer detected and only returns after the $3-4^{\text {th }}$ week of postnatal 
life. After birth, there is a progression in the maturation of the circadian system and sleep-wake rhythm, and after the second month of life, the secretion of melatonin develops. At three months old, a relative distribution of sleep and wakefulness occurs during the 24 hours and the maximum period of continuous sleep is three and a half hours. During the first six months of life, major changes are seen in the duration and distribution of sleep; the consolidation of sleep occurs in this phase, and this is distributed during the night, with naps during the day. At six months, the longest uninterrupted sleep period is six hours and this period is followed by a long period of wakefulness ${ }^{1,7,15}$.

In the fetal period, sleep is divided into stages, which are Active Sleep (AS), Quiet Sleep (QS) and Indeterminate Sleep (IS). AS is compatible with Rapid Eye Movement (REM) sleep in adults. This is the first type of sleep existing in ontogeny, and it can already be identified in the $28-30^{\text {th }}$ week of gestation. It is controlled by the forebrain and brainstem and it is characterized by REM, high physiological activity, irregular breathing and greater heart beat supply of oxygen to the brain. In this sleep it is also possible to observe muscle atonia that also affects the muscles involved in breathing, such as the intercostal muscles and the upper airway, although the diaphragm still retains its function ${ }^{12}$. In adults it is possible to observe the tonic movements of members, but in fetuses and premature infants it is very difficult to assess this parameter, because the movements of tonic activity before the $36^{\text {th }}$ week of pregnancy are very scarce. It is in AS that the maturation and differentiation of the CNS and memory consolidation occur and learning patterns of emotional behavior develop ${ }^{7,12,13,16,17}$.

QS, compatible with Non Rapid Eye Movement sleep (NREM) in adults, is already identified in the electroencephalogram at 32 weeks of gestation, but is only well developed in the $36-38^{\text {th }}$ week of gestation. It is formed after stabilization networks of specific excitatory and inhibitory components of the thalamus and cortex. It is characterized by rest period, energy maintenance, increased protein synthesis and release of growth hormone, during which there are sucking movements, smiles, slight blinking, faces and trembling; breathing and heart rate are regular and eye movements are absent or regular ${ }^{7,12,13,16,17}$. The pattern, as well as breathing pauses and interaction between abdominal and thoracic breathing, distinguish AS and $\mathrm{QS}^{7,15}$. IS is the period in which neither quiet nor restless sleep can be identified ${ }^{7}$.

\section{Sleep evaluation}

In the early stages of mammal's life, most sleep is AS, so even the identification of QS becomes difficult and is better identified by an alternative EEG route. Over time, the sleep pattern evolutes due to neurophysiological development, thus decreasing the amount of AS, while QS increases and becomes dominant at three months of age, when it represents $30 \%$ of the total amount of sleep and is half of the amount of $\mathrm{AS}^{7,15,16}$.

The fetus sleep ontogeny plays a critical role in early brain development, regulating arousal, attention and cognition due to developmental plasticity ${ }^{18}$. The sleep pattern is one of the best ways to evaluate the neurobehavioral development of preterm sleep in short-term indicators, as the sleep-wake states are sensitive gauges of maturation and organization of the CNS and can predict future problems ${ }^{7,19}$. The number of arousals reflects the progressive activation of cortical and subcortical areas. The subcortical arousals decrease with maturation, both in AS and in QS, while cortical arousals increase in AS and decrease in QS. This is due to the fact that the structures and mechanisms involved in AS and QS are distinct. The level of cortical activity in AS is more related to wakefulness than QS, and in QS there are greater inhibitory influences that minimize awakenings $\mathrm{s}^{7,13,16,20,21}$.

In preterm infants at 31 weeks of gestation, respiratory regularity informs the period of the sleep state ${ }^{22}$. Preterm infants spend more time awake than in AS and this pattern remains until six months of age. They have a less organized sleep with high discrepancy between the behavior and the EEG variables analyzed ${ }^{7,18,16,19}$. The proportions of sleep stages change all the time, but AS corresponds to $90 \%$ of sleep for those born at 30 weeks gestation and to $50 \%$ in term infants ${ }^{7,13,15,17}$. In EEG of premature who have reached 40 weeks of post-gestational age, the results indicate that they still have a sleep with a low degree of organization and with less QS compared to those born term ${ }^{7,15}$. Severe neurological damage is associated with longer periods in $\mathrm{AS}^{7,17}$.

Premature have more episodes of apnea, respiratory periods of absence of respiratory efforts with time duration of 2 breathing cycles or 2 or 3 seconds for the duration of apneas for newborns. The highest number of episodes is linked to the most immature neurological system and respiratory system, the largest number of infections and gastrointestinal problems. Apneas are most common during the phase of AS and can be classified as central, obstructive and mixed apnea. The central apnea results from a disorder in the central control of breathing; in this case, there is an absence of breathing efforts and airflow. Obstructive apnea results from an obstruction of the airways; in this case, there is respiratory effort but no airflow. Mixed apnea mostly initially follows central apnea that evolves to an obstructive case $e^{20,23}$. However, mixed apneas can also occur in the other sense to first be part obstructive and after central type in babies.

\section{Polysomnography and neurodevelopment of premature neonates}

One of the parameters of sleep analysis is the video-polysomnography indicated for the newborn, which can detect cardio-respiratory episodes and confirm abnormalities in the EEG, or rule out respiratory changes before discharge, 
by assessing the neurological and cardio-respiratory patterns in relation to sleep stage and gestational age $\mathrm{e}^{24}$. Among all of the possible parameters to be measured by polysomnography, the most frequent refer to reviewing the progress and quality of sleep of premature neonates ${ }^{24,25}$. Polysomnography allows the calculation of total sleep time, defined as the total sleep period minus the duration of wakefulness, sleep efficiency given by the ratio of total sleep time over the total sleep period, percentage of QS, percentage of AS and percentage of wakefulness ${ }^{7,13,17,20,21,22}$.

There are currently computational, mathematical and statistical studies being developed to differentiate the polysomnography of premature neonates, defining specific channels to capture the phases of AS and QS in preterm infants. This facilitates the assessment of maturation of the brain of these children in studying the structure and temporal patterns of their sleep. The study proposes a proper selection of EEG channels and most suitable characteristics for the separation of the state of sleep in EEG in this specific population ${ }^{26}$.

\section{Pain and prematurity}

In thirty years the understanding of pathophysiological mechanisms of pain in the newborn has achieved significant progress. There is evidence that the foetus at mid-pregnancy, and the newborn, are capable of feeling pain, the same being assessed indirectly by increasing heart rate, blood cortisol and beta-endorphin in response to activation of their autonomous nervous system ${ }^{27,28,29,30}$. This perception would be an inherent quality of life, which appears early in ontogeny, and serves as a signalling system for tissue damage. Pain in the newborn is usually acute, caused by noxious stimuli known as tissue trauma, has relatively short duration and is a fifth vital $\operatorname{sign}^{31}$. Its perception is multidimensional and varies in quality, intensity, duration, location and symbolic image, according to the characteristics of each individual. Factors such as age, previous painful experience, cognition, learning, psychomotor stage, use of sedatives and analgesics and family conditions can modify the expression of pain, and this makes it more difficult to quantify and qualify in healthy term and premature neonates ${ }^{27,28,32}$.

One of the arguments to the claim that the newborn cannot perceive pain is the cortical immaturity. However, the cortical processing involved in nociception was shown by Slater et al. ${ }^{32}$. A late component (N420 - P560) of the EEG response at $\mathrm{Cz}$ and $\mathrm{CPz}$ was found in 12 babies between 35 and 39 weeks of gestation and was discriminated between the experimental condition and non-harmful conditions. This represented a specific nociceptive potential, and was not dependent on the state of sleep ${ }^{33}$. Furthermore, myelination of the nerve fibers occurs around the $13^{\text {th }}$ week and the formation of synapses of thalamic tracts occurs at about the $24^{\text {th }}$ week of pregnancy (it is inferred that the specific thalamic pain fibers are included) and by this time the neocortex has reached its full size.
The painful experience can bring on premature metabolic changes, a rise in hormone levels, changes in the already delicate balance between sleep and wakefulness and blood flow, among others ${ }^{34}$. Invasive procedures and stressors of NICU cause an aversive behavior that can lead the child to associate any touch with pain, triggering responses such as crying and gathering hands and legs. Repeated painful exposures are associated with a low regulation of the hypothalamicpituitary-adrenal (HPA) axis, which cannot react to morphine, as well as hypo or hyper-cortisol response to stress ${ }^{31,32}$.

\section{Pain measurements in neonatal intensive care unit}

Starting from the evidence that the infant has pain perception, not pegged only to the physical sensation, but involving cognitive and emotional systems, it is natural to question the measurement and interpretation of non-verbal pain levels in these individuals. Thus, researchers have developed numerous psychophysical scales aimed at measuring the perception of pain based on physiological and behavioral indicators, among different neonates. These include physiologic assessments, such as the heart and respiratory rate, intracranial pressure, palm sweating, hormonal levels, vagal tone and variability of oxygen saturation and blood pressure parameters that can be displayed by newborns $^{35}$. Advocates for behavioral assessment scales suggest analyzing facial expression (e.g. NFCS), cry vocalizations, and the waking state (e.g. PIPP) $)^{34}$. Along with that, there is the context in which the child is also to be analyzed, since these responses are not specific to painful stimulation.

There are thus a relatively large number of pain scales applied to studying newborns, some focused only on observational behavior and others on balancing physiological and behavioral aspects, which are called one-dimensional and multidimensional scales, respectively ${ }^{36}$. The validity of these scales is questioned by scientists in terms of the specificity of patients that can be evaluated (preterm, at-term or postterm neonates), the level of risk to the integrity of the CNS, which is difficult to analyze in sick babies or in critical NICU situations ${ }^{37}$.

To validate new devices for pain assessment, it is mandatory to choose comparable instruments, and the methodology employed in these instruments of pain assessment should be considered, since there are different theoretical models in use. Differences in theoretical and methodological approaches also have implications for differences in how the measurements are taken and analyzed. Therefore, use of pain scales in clinical settings and research should be aligned with other validated measures that allow doctors to compare the indicators of pain for every child before, during and after a painful procedure, so they can make decisions on maneuvers to ease or stop the pain. It is therefore difficult to propose, for each type of existing measure, a cut off point or the absolute threshold of pain. Hence, the great variability between the 
responses of children does not allow a universal score for pain $^{38}$. The dimensions of these physiological indicators can be described through psychophysical parameters of intensity, direction, reactivity, regulation and slope. These parameters are used in the field of psychophysics to interpret the response to pain, considering three time points: baseline measurements, responsiveness to painful stimulus and recovery ${ }^{27}$.

Slater et al. made a correlation of painful stimuli received during invasive procedures (venous puncture, calcaneus), increased use of ATP and oxidative stress. To measure this stressful effect of pain, a pain scale (PIPP) and increased serum levels of uric acid and malondialdehyde (MDA) in plasma obtained before and after the puncture procedure were used. Uric acid is the end product of the purine metabolism, and its concentration is associated with increased ATP utilization, hypoxia, ischemia and increased reactivity with oxygen species (ROS). MDA is a thiobarbituric formed by the action of ROS in lipid membranes. Use of this tag is relevant because although the study of oxidative stress and pain is relatively new, the association of pain with increased MDA is not new and has been reported in adults with neuropathic, abdominal and vascular pain ${ }^{39}$.

\section{Sleep and pain in intensive care}

The interdependent relationship between sleep and pain was initially posited by Lewin and Dahl in 1999 when they found that not only does pain interfere with the quantity and quality of sleep in children, but it is also likely that insufficient sleep causes sequels throughout the day that sensitize the child to experiencing pain and other somatic symptoms ${ }^{40}$. These authors also suggest that fear and anxiety often have a negative impact on pain and sleep, while feelings of safety and control often have a positive effect on sleep and pain symptoms. Furthermore, adequate sleep seems to promote both physiological (tissue repair) and psychological (temporary cessation of perception of pain signals) relevant to recovery from pain, injury and disease processes, and treatment approaches for pediatric sleep problems and pain show considerable overlap with respect to many pharmacological and cognitive-behavioral interventions. In both adult and pediatric intensive care units, sleep may be impaired because of the patient's critical condition and the procedures performed, the mechanisms of occurrence are still poorly understood. Approximately $20 \%$ of awakenings are related to noise and $10 \%$ to nursing interventions or medicine. The constant interventions create fragmentation of sleep, which leads to a lower total sleep time (TST), which can lead to sleep deprivation ${ }^{7,41}$.

Changes in sleep and painful experiences are both suspected of contributing to poor neurodevelopmental outcomes, especially in newborns with very low birth weight. Few studies have explored the interrelationship between the two conditions. Research on neurogenesis in adult rats deprived of sleep has shown that deprivation led to a reduction of up to $35 \%$ of proliferating cells identified by markers for bromodeoxyuridine (BrdU), and thus labeled BrdU cells. These data indicate the possible reduction of around $60 \%$ in the number of new neurons being produced after sleep deprivation. Evidence from these studies supports the hypothesis that sleep deprivation is associated with compromising the proliferation of granule cells of the dentate gyrus in the adult hippocampus ${ }^{42}$.

The intrinsic question is to what degree pain can enhance changes in the sleep-wake cycle, and if this cycle is changed, can the perception of pain by the baby also be changed. In a situation such as continued exposure to pain due to a tracheal intubation procedure, which changes the sleep-wake cycle, there may also be suppression or deprivation of sleep and the effects on subsequent development can be of a behavioral and biochemical nature ${ }^{43}$. Extreme-preterm infants receiving ventilatory support due to significant morbidities exhibit a measurable delay in the maturation of sleep architecture ${ }^{44}$. Studies with animal models show evidence of these implications, such as reduced exploratory behavior and learning difficulties, attention problems, anxiety, shrinkage of the brain, developmental disorders and decreased memory function of the posterior hippocampus and brain plasticity ${ }^{43}$.

\section{Intervention programs in Neonatal Intensive Care, related to sleep and pain}

Many programs and therapeutic techniques have been created in Europe, North America, Latin America and Asia to minimize the negative impacts of intensive care on premature neonates. The goal is to make the experience of these newborns as stable and well organized as possible by strengthening family ties and reducing stress agents working in the vestibular, auditory, visual and tactile stimuli. Among these programs, one can cite the Newborn Individualized Development Care and Assessments (NIDCAP) developed in the USA in 1986 by $\mathrm{Als}^{2,44,45,46,47,48,49}$.

NIDCAP is the predominant model in the USA, Argentina, Belgium, France, Sweden, Holland and the UK. Dealing concurrently with five subsystems within the infant's behavior, and known as synactive theory, it is an intervention that attempts to minimize the impacts on the immature brain from noxious sensory experiences in the environment and procedures of a NICU, promoting the proper sensory stimulation for the levels of the child's neurological maturation. NIDCAP emphasizes individualized care by increasing the positive results in the prevention of neurodevelopmental delay, by reducing noxious stimuli. This individualized childcare involves a formal sequence and naturalistic observations of the priorities and responses during and after procedures performed. For its implementation, a multidisciplinary team of physicians, nurses, social workers, psychologists, 
nutritionists and parents is required. It is organized so that the NICU is adapted to an exclusive room for preterm neonates. One major goal is to make this team, which includes parents, become more sensitive to the signals produced by the child, increasing interaction with her/him and participating in her/his care, when possible ${ }^{4,6,50}$.

NIDCAP is also concerned with sleep in preterm infants, and promotes restful moments in which the child can sleep peacefully, with decreased sleep fragmentation, improving the development of nocturnal sleep and of circadian organization. Less fragmentation also increases stability due to fewer cardiac adverse stimuli, lower frequency and duration or severity of bradycardia, apnea and oxygen desaturation, lower physical demands, minimization of metabolic needs and increased $\mathrm{QS}^{8,51}$. Studies recording the differences between the sleep of premature neonates in standard NICU care and those cared for by NIDCAP show that the total amount of uninterrupted sleep in the NIDCAP group is larger, so both AS and QS increase $e^{8,52,53,54,55}$.

Studies showing the actual effects of NIDCAP on sleep are scarce and controversial. A study that analyzed the impact of NIDCAP asleep in 36 week neonates, at 4, 12 and 24 months after the post-conceptional age indicated that NIDCAP had no impact on the amount of peaceful sleep $^{45}$. Another study observed no significant effect of light on the circadian rhythm in preterm infants of 36 weeks with a three-month corrected age ${ }^{55}$. Bertelle et al, in a study with polysomnography, identifying the total amount of sleep, duration of AS, QS, IS and latency before sleep in preterm newborn when the care of the development is applied noted a positive impact on sleep duration, with a $20 \%$ increase in the amount of sleep and evidence of the association of a sustained period of calm sleep with a decrease in the amount of indeterminate sleep, sleep latency and a decrease in the number of apneas lasting longer than 15 seconds $^{54}$.

Kangaroo Mother Care (KMC) another kind of care program promotes the early skin-to-skin contact between the mother and the child ${ }^{9}$. In $\mathrm{KMC}$, the incubator is progressively replaced by the mother and the baby is kept warm through skin to skin contact. The benefits of the method include reduction in morbidity and length of hospitalization of infants and improvement in the incidence and duration of breastfeeding and the sense of responsibility of parents ${ }^{49,50,51}$. In Europe is called Kangaroo Care, and consists of skin-toskin mother-infant contact for a few hours per day. In a group of premature who received KMC for a period of eight weeks when compared with conventional care, it was concluded that this method results in an accelerated neurophysiological development, a more organized sleep behavior after a single session and showed a change in the organization and maturation of sleep, confirming the concept of premature adaptation to therapeutic interventions. In addition, $\mathrm{KMC}$ as a method of managing induced pain was associated with the deepest sleep during the recovery period of two minutes compared to no treatment and in infants at 32 weeks gestation improved the state of organization of NREM sleep and wakefulness, increasing alertness, and improving the sleep-wake cycle ${ }^{56,57,58,59}$.

Another study about neurophysiological maturation evaluated the intervention of $\mathrm{KMC}$ in the premature brain, when compared to controls who did not receive this care through EEG during the sleep suggests that skin-to-skin contact produces a faster neurophysiological maturation and that the maturation of the left hemisphere was more advanced in the KMC group. This study speculated that the more advanced cortico-cortical type connections are in early life, preferably the left hemisphere, particularly with respect to increased responsiveness to this hemisphere sensory stimulation. This hemispheric response to sensory input has been demonstrated in other studies based on the reaction of newborns to stimulation of pain, as well as the processing of voice and tone detection and discrimination. These functions can be active as early as 30 weeks of gestational age in the foetal brain ${ }^{60}$.

\section{FINAL REMARKS}

Sleep is the predominant behavioral state in the premature neonate and is involved in maturation and brain development. It is important that professionals working in NICU know how to differentiate the states of sleep and wakefulness, through observation of the characteristics of each phase, so that they may conduct their activities without interfering with the sleep and brain development of the premature behavioral states. Polysomnography continues to be the gold standard for sleep state studies and clinical neurological assessment of the preterm neonate ${ }^{15}$.

Sleep deprivation has been portrayed as one of the biggest stressors for the patient. It has a negative impact on the pattern of behavior, on breathing, and on neuronal development, and it is associated with hospital and medical disorders. Sleep disorders cause the induction of sympathetic activity and high blood pressure that may contribute to increased morbidity of patients ${ }^{7,13,45}$.

Bringing together the benefits found in the studies on NIDCAP and kangaroo care, it can be said that there are reports of many benefits from the kangaroo position in stabilizing the infant's temperature through maternal temperature, in easing respiratory efforts in accordance with the natural maternal posture, and in increasing periods of restful sleep needed for growth, weight gain and neurological development in infants ${ }^{60,61}$.

The development of sleep is one of the parameters to assess the maturation of the CNS, and it is still poorly explored both in clinical situations and in research, in part 
due to the lack of knowledge about what each of the indicators may mean. However, in recent decades their use has allowed progress in the exploration of specific neural development in children born preterm. In this review it can be seen that the premature baby has a late maturation pattern for the main indicators of sleep, due to the condition of her/his CNS at birth and the interaction of this with the adversities of the hospital environment.

Monitoring the development of children participating in programs designed to minimize the negative impact of hospitalization has shown gains, such as better neurophysiological development, an increase in the uninterrupted period of QS, a decrease in the amount of IS, sleep latency and a decrease in the number of apneas. These data have been interpreted as evidence that these intervention programs promote acceleration, organization and maturation of sleep states. However, longitudinal studies should be conducted to verify the long-term impact of these programs, including checking for other variables such as the baby's social interaction.

\section{References}

1. Begum E, Bonno M, Obata M, Yamamoto H, Kawai M, Komada Y Emergence of physiological rhythmicity in term and preterm neonates in a neonatal intensive care unit. J Circad Rhythms. 2006;4:11.

2. Als H, Lawhon G, Duffy FH, McAnulty GB, Gibes-Grossman R, Blickman JG. Individualized developmental care for the very low-birthweight preterm infant. Medical and neurofunctional effects. JAMA. 1994;272:(11)853-8. http://dx.doi.org/10.1001/jama.1994.03520110033025

3. Kleberg A, Hellström-Westas L, Widström A. Mothers' perception of Newborn Individualized Developmental Care and Assessment Program (NIDCAP) as compared to conventional care. Early Hum Dev. 2007;83(6):403-11. http://dx.doi.org/10.1016/j.earlhumdev.2006.05.024

4. Kleberg A, Westrup B, Stjernqvist $\mathrm{K}$, Lagercrantz $\mathrm{H}$. Indications of improved cognitive development at one year of age among infants born very prematurely who received care based on the Newborn Individualized Developmental Care and Assessment Program (NIDCAP). Early Hum Dev. 2002;68(2):83-91. http://dx.doi.org/10.1016/S0378-3782 (02)00014-2

5. Grieve PG, Isler JR, Stark RI. EEG functional connectivity in term age extremely low birth weight infants. Int J Clin Neuropsychol. 2008;19:2712-20.

6. Butler $\mathrm{S}$, Als $\mathrm{H}$. Individualized developmental care improves the lives of infants born preterm. Acta Paediatr. 2008;97(9):1173-5. http://dx. doi.org/10.1111/j.1651-2227.2008.00916.x

7. Hoppenbrouwers T, Hodgman JE, Rybine D, Fabrikant G, Corwin M, Crowell $D$ et al. Sleep architecture in term and preterm infants beyond the neonatal period: the influence of gestational age, steroids and ventilatory support. Sleep. 2005;28(11):1428-36.

8. Ariagno RL, Thoman EB, Boeddiker MA, Kugener B, Constantinou JC, Mirmiran $\mathrm{M}$ et al. Developmental care does not alter sleep and development of premature infants. Pediatrics. 1997;100(6):E9. http:// dx.doi.org/10.1542/peds.100.6.e9

9. Azevedo VMGO, David RB, Xavier CC. Cuidado mãe canguru em recémnascidos pré-termo sob suporte ventilatório: avaliação dos estados comportamentais. Rev Bras Saude Mater Infant. 2011;11(2):133-8. http://dx.doi.org/10.1590/S1519-38292011000200004

10. Geib LTC. Development of sleep stages in childhood. Rev Bras Enferm. 2007;60(3):323-6. http://dx.doi.org/10.1590/S0034-71672007000300014

11. Kahn A, Dan B, Groswasser J, Franco P, Sottiaux M. Normal sleep architecture in Infants and children. J Clin Neurophysiol. 1996;13(3):184-97. http://dx.doi.org/10.1097/00004691-199605000-00002

12. Mirmiran M, Someren EV. The importance of REM sleep for brains maturation. J Sleep Res. 1993;2(4):188-92.

13. Peever JH, McGinty D. Why do we sleep? In: Lavigne G, Sessle B, Choinière M, Soja P, editors. Sleep and pain. Seattle: IASP Press, 2007. p. 1-8.

14. Montemitro MD, Scaillet S, Kato I, Groswasser J, Villa MP, Kahn A et al. Maturation of spontaneous arousals in healthy infants. Sleep. 2008;31(1):47-54.
15. Mirmiran M, Ariagno RL. Influence of light in the NICU on the development of circadian rhythms in preterm infants. Semin Perinatol. 2006;24(4):247-57. http://dx.doi.org/10.1053/sper.2000. 8593

16. Brandon DH, Holditch-Davis D, Winchester DM. Factors affecting early neurobehavioral and sleep outcomes in preterm infants. Infant Behav Dev. 2005;28(2):206-19. http://dx.doi.org/10.1016/j.infbeh.2005.02.005

17. Van den Bergh BRH, Mulder EJHJ. Fetal sleep organization: a biological precursor of self-regulation in childhood and adolescence? Biol Psychol. 2012;89(3):584-90. http://dx.doi.org/10.1016/j.biopsycho.2012.01.003

18. Anders T, Emde K, Paermelle A. A manual of standardized terminology, techniques and criteria for scoring of states of sleep and wakefulness in newborn infants. Los Angeles: UCLA Brain Information Service; 1971.

19. Bhat RY, Hannam S, Pressler R, Rafferty GF, Peacock JL, Greenough A. Effect of prone and supine position on sleep, apneas and arousal in preterm infants. Pediatrics. 2005;118(1):101-7. http://dx.doi.org/ 10.1542/peds.2005-1873

20. Gerhardt T, Bancalari E. Apnea of prematurity: I. Lung function and regulation of breathing. Pediatrics. 1984;74(1):58-62.

21. Lester KR, Puerta RJ, Lahorgue NM. Behavioral assessment of sleep state in newborns. J Epilepsy Clin Neurophysiol. 2009;15:25-9.

22. Bhatia J. Current options in the management of apnea of premature. Clin Pediatr. 2000;39(6):327-36. http://dx.doi.org/10.1177/ 000992280003900602

23. Parthasarathy S, Tobin MJ. Sleep in the intensive care unit. Intens Care Med. 2004;30(2):197-206. http://dx.doi.org/10.1007/s00134003-2030-6

24. Sloan NL, Camacho LW, Pinto Rojas E, Stern C, Maternidad Isidro Ayora Study Team. Kangaroo mother method: randomised controlled trial of an alternative method of care for stabilised low-birthweight infants. Lancet. 1994;344(8925):782-5. http://dx.doi.org/10.1016/ S0140-6736(94)92341-8

25. Piryatinska A, Woyczynski WA, Scher MS, Loparo KA. Optimal channel selection for analysis of EEG-sleep patterns of neonates. Comput Meth Prog Bio. 2012;106(1):14-26. http://dx.doi.org/10.1016/j. cmpb.2011.08.002

26. Stevens BJ, Riddell RRP, Oberlander TE, Gibbins S. Assessment of pain in neonates and infants. In: Anand KJS, Stevens BJ, McGrath PJ, editors. Pain in neonates and infants. Philadelphia: Elsevier; 2007.

27. Goldman RD, Koren G. Biologic markers of pain in the vulnerable infant. Clin Perinatol. 2002;29(3):415-25. http://dx.doi.org/10.1016/ S0095-5108(02)00014-3

28. Ginnakoulopoulos X, Sepulveda W, Kourtis P, Glover V, Fisk NM. Fetal plasma cortisol and beta-endorphin response to intrauterine needling. Lancet. 1994;344(8915):77-81. http://dx.doi.org/10.1016/ S0140-6736(94)91279-3 
29. Anand KJS, Carr DB. The neuroanatomy, neurophysiology, and neurochemistry of pain, stress, and analgesia in newborns and children. Pediatr Clin North Am. 1989;36(4):795-822.

30. Landrot IDR, Roche F, Pichot V, Teyssier G, Gaspoz JM, Barthelemy $\mathrm{JC}$, Patural $\mathrm{H}$. Autonomic nervous system activity in premature and full-term infants from theoretical term to 7 years. Auton Neurosci. 2007;136(1-2):105-9. http://dx.doi.org/10.1016/j.autneu. 2007.04.008

31. Okada M, Teixeira MJ, Tengan SK, Bezerra SL, Ramos CA. Pain in pediatrics. Rev Med (São Paulo). 2001;80(esp pt 1):135-56.

32. Slater R, Worley A, Fabrizi L, Roberts S, Meek J, Boyd S et al. Evoked potentials generated by noxious stimulation in the human infant brain. Eur J Pain. 2010;14(3):321-6. http://dx.doi.org/10.1016/j. ejpain.2009.05.005

33. Anand KJ. Effects of perinatal pain and stress. Prog Brain Res. 2000;122:117-29. http://dx.doi.org/10.1016/S0079-6123(08)62134-2

34. Pereira ALST, Guinsburg R, Almeida MFB, Santos AMN, Kopelmanet BI. Validity of behavioral and physiologic parameters for acute pain assessment of term newborn infants. Sao Paulo Med J.1999;117(2):72-80. http://dx.doi.org/10.1590/S1516-31801999000200005

35. Beacham PS. Behavioral and physiological indicators of procedural and postoperative pain in high-risk infants. J Obstet Gynecol Neonatal Nurs; 2006;33(2):246-55. http://dx.doi.org/10.1177/ 0884217504263267

36. Baeyer CL, Spagrud LJ. Systematic review of observational (behavioral) measures of pain for children and adolescents aged 3 to 18 years. Pain. 2007;127(1-2):140-50. http://dx.doi.org/10.1016/j. pain.2006.08.014

37. Oliveira MVM, Jesus JAL, Tristao RM. Psychophysical parameters of a multidimensional pain scale in new borns. Physiol Meas. 2012;33(1):39-49. http://dx.doi.org/10.1088/0967-3334/33/1/39

38. Jesus JAL, Tristao RM, Storm H, Rocha A, Campos Junior D. Heart rate, oxygen saturation, and skin conductance: a comparison study of acute pain in Brazilian new borns. Conf Proc IEEE Eng Med Biol Soc. 2011:1875-9. http://dx.doi.org/10.1109/IEMBS.2011.6090532

39. Slater L, Asmerom Y, Boskovic DS, Bahjri K, Plank MS, Angeles KR et al. Procedural pain and oxidate stress in premature neonates. J Pain. 2012;13(6):590-7. http://dx.doi.org/10.1016/j.jpain.2012.03.010

40. Lewin DS, Dahl RE. Importance of sleep in the management of pediatric pain. J Dev Behav Pediatr. 1999;20(4):244-52.

41. Parthasarathy S, Tobin MJ. Sleep in the intensive care unit. Intens Care Med. 2004;30(2):197-206. http://dx.doi.org/10.1007/s00134003-2030-6

42. Guzman-Marin R; Suntsova N; Bashir T; Nienhuis R; Szymusiak R; McGinty D. Rapid eye movement sleep deprivation contributes to reduction of neurogenesis in the hippocampal dentate gyrus of the adult rat. Sleep. 2008;31(2):167-75.

43. Axelin A, Kirjavainen J, Salanterä S, Lehtonen L. Effects of pain management on sleep in preterm infants. Eur J Pain. 2010;14(7):751-8. http://dx.doi.org/10.1016/j.ejpain.2009.11.007

44. Hoppenbrouwers T, Hodgman JE, Rybine D, Fabrikant G, Corwin M, Crowell $D$ et al. Sleep architecture in term and preterm infants beyond the neonatal period: the influence of gestational age, steroids, and ventilatory support. Sleep. 2005;28(11):1428-36.

45. Westrup B, HellstromWestas L, Stjernqvist K, Laagercrantz H. No indications of increased quiet sleep in infants receiving care based on the Newborn Individualized Developmental Care and Assessment Program (NIDCAP). Acta Paediatr. 2002;91(3):318-22. http://dx.doi. org/10.1111/j.1651-2227.2002.tb01722.x
46. Ozawa M, Sasaki M, Kanda K. Effect of procedure light on the physiological responses of preterm infants. Jpn J Nurs Sci. 2010;7(1):76-83. http://dx.doi.org/10.1111/j.1742-7924.2010.00142.x

47. Symington A, Pinelli J. Developmental care for promoting development and preventing morbidity in preterm infants. Cochrane Database Syst Rev. 2006;(2):CD001814.

48. Als $\mathrm{H}$. Developmental care in the newborn intensive care unit. Curr Opin Pediatr. 1998;10(2):138-42. http://dx.doi.org/10.1097/00008480199804000-00004

49. Tessier R, Cristo M, Velez S, Giron M, Calume ZF, Ruiz-Pelaez JG et al. Kangaroo mother care and the bonding hypothesis. Pediatrics. 1998;102(2):e17. http://dx.doi.org/10.1542/peds.102.2.e17

50. Cattaneo A, Davanzo R, Uxa F, Tamburlini G; International Network on Kangaroo Mother Care. Recommendations for the implementation of kangaroo mother care for low birth weight infants. Acta Paediatr. 1998;87(4):440-5. http://dx.doi.org/10.1111/j.1651-2227.1998.tb01475.x

51. Charpak N, Ruiz Peláez JG, Calume ZF, Charpak Y. Kangaroo mother versus traditional care for newborn infants $\leq 2000$ grams: a randomized controlled trial. Pediatrics. 1997;100(4):682-8. http://dx. doi.org/10.1542/peds.100.4.682

52. Im H, Kim E, Cain KC. Acute effects of Yakson and Gentle human touch on the behavioral state of preterm infants. J Child Health Care. 2009;13(3):212-26. http://dx.doi.org/10.1177/1367493509337441

53. Als H, Butler S, Kosta S, McAnulty G. The Assessment of Preterm Infants' Behavior (APIB): furthering the understanding and measurement of neurodevelopmental competence in preterm and full-term infants. Ment Retard Dev Disabil Res Rev. 2005;11(1):94-102. http:// dx.doi.org/10.1002/mrdd.20053

54. Bertelle V, Mabin D, Adrien J, Sizun J. Sleep of preterm neonates under developmental care or regular environmental conditions. Early Hum Dev. 2005;81(7):595-600. http://dx.doi.org/10.1016/j.earlhumdev.2005.01.008

55. Mirmiran M, Baldwin RB, Ariagno RL. Circadian and sleep development in preterm infants occurs independently from the influences of environmental lighting. Pediatr Res. 2003;53(6):933-8. http://dx. doi.org/10.1203/01.PDR.0000061541.94620.12

56. Scher MS, Ludington-Hoe S, Kaffashi F, Johnson MW, Holditch-Davis D, Loparo KA. Neurophysiologic assessment of brain maturation after an 8-week trial of skin-to-skin contact on preterm infants. Clin Neurophysiol. 2009;120(10):1812-8. http://dx.doi.org/10.1203/01. PDR.0000061541.94620.12

57. Castral TC, Warnock F, Leite AM, Haas VJ, Scochi CG. The effects of skin-to-skin contact during acute pain in preterm newborns. Eur J Pain. 2008;12(4):464-71. http://dx.doi.org/10.1016/j.ejpain.2007.07.012

58. Feldman R, Weller A, Sirota L, Eidelman Al. Skin-to-skin contact (kangaroo care) promotes self-regulation in premature infants: sleepwake cyclicity, arousal modulation, and sustained exploration. Dev Psychol. 2002;38(2):194-207. http://dx.doi.org/10.1037/0012-1649.38.2.194

59. Feldman R, Eidelman Al. Skin-to-skin contact (kangaroo care) accelerates autonomic and neurobehavioural maturation in preterm infants. Dev Med Child Neurol. 2003;45(4):274-81. http://dx.doi.org/ 10.1111/j.1469-8749.2003.tb00343.x

60. Kaffashi F, Scher MS, Ludington-Hoe SM, Loparo KA. An analysis of the kangaroo care intervention using neonatal EEG complexity: a preliminary study. Clin Neurophysiol. 2013;124(2):238-46. http://dx. doi.org/10.1016/j.clinph.2012.06.021

61. Smith, KM. Sleep and kangaroo care: clinical practice in the newborn intensive care unit: where the baby sleeps. J Perinat Neonat Nur. 2007;21(2):151-7. http://dx.doi.org/10.1097/01.JPN.0000270633.81616.62 